CARDIOVASCULAR MEDICINE

\title{
Management and in-hospital outcome of patients with acute myocardial infarction admitted to intensive care units at the turn of the century: results from the French nationwide USIC 2000 registry
}

\author{
G Hanania, J-P Cambou, P Guéret, L Vaur, D Blanchard, J-M Lablanche, Y Boutalbi, R Humbert, \\ $P$ Clerson, N Genès, N Danchin, for the USIC 2000 Investigators
}

Heart 2004;90:1404-1410. doi: 10.1136/hrt.2003.025460

See end of article for authors' affiliations

Correspondence to: Dr Nicolas Danchin, Service de Cardiologie, Hôpital Européen Georges Pompidou, 20 rue Leblanc, 75015 Paris, France; nicolas.danchin@ egp.ap-hop-paris.fr

Accepted

18 December 2003

\begin{abstract}
Objective: To assess actual practices and in-hospital outcome of patients with acute myocardial infarction on a nationwide scale.

Methods: Of 443 intensive care units in France, $369(83 \%)$ prospectively collected data on all cases of infarction (within $<48$ hours of symptom onset) in November 2000.

Results: 2320 patients (median age 68 years, $73 \%$ men) were included, of whom $83 \%$ had ST segment elevation infarction (STEMI). Patients without STEMI were older and had a more frequent history of cardiovascular disease. Median time to admission was 5.0 hours for patients with and 6.5 hours for those without STEMI. Reperfusion therapy was used for $53 \%$ of patients with STEMI (thrombolysis $28 \%$, primary angioplasty $25 \%$ ). In-hospital mortality was $8.7 \%$ (5.5\% of patients without and $9.3 \%$ of those with STEMI). Multivariate analysis found that age, Killip class, lower blood pressure, higher heart rate on admission, anterior location of infarct, STEMI, diabetes mellitus, previous stroke, and no current smoking independently predicted in-hospital mortality. At hospital discharge, $95 \%$ received antiplatelet agents, $75 \%$ received $\beta$ blockers, and over $60 \%$ received statins. Angiotensin converting enzyme inhibitors were prescribed for $40 \%$ of the patients without and $52 \%$ of those with ST elevation.

Conclusions: This nationwide registry, including all types of centres irrespective of their size and experience, shows continued improvement in patient care and outcomes. Time from symptom onset to admission, however, has not improved in recent years and reperfusion therapy is used for just over $50 \%$ of patients with STEMI, with an increasing use of primary angioplasty.
\end{abstract}

$\mathrm{T}$ he 1990s have provided a large amount of information on the optimal management of patients with acute myocardial infarction, both in terms of acute reperfusion therapy and of secondary prevention. Guidelines have been published that specify the optimal treatment strategies for such patients. ${ }^{12}$ Few data, however, are available regarding the way these guidelines translate into real life clinical practice. Several important registries have provided useful information but they usually included only specially motivated centres ${ }^{3}$ or selected populations, ${ }^{4}$ and their conclusions therefore may not reflect what truly happens on a wider scale in the real world. The USIC (Unité de Soins Intensifs Coronaires) 2000 survey is a prospective registry of all patients admitted to intensive care units in France for acute myocardial infarction by the end of 2000 . The purpose of the present study is to describe the baseline clinical profile of the patients, their initial management and in-hospital outcome, and the medications prescribed at discharge.

\section{METHODS \\ Population}

The objective of the USIC 2000 study was to gather complete and representative data on the management and outcome of patients admitted to intensive care units for acute myocardial infarction over a one month period in France, irrespective of the type of institution to which the patients were admitted (that is, university hospitals, public hospitals, or private clinics). To this purpose, a list of all intensive care units or coronary care units admitting patients at the acute stage of myocardial infarction was established at the beginning of 2000. All physicians in charge of these units were then asked to participate in the study. In all, 443 centres were listed: 49 university hospitals, 271 public hospitals, and 123 private clinics. Of these, 369 finally participated in the study (83\%). The participation rate was $90 \%(\mathrm{n}=44)$ for university hospitals, $84 \%(n=228)$ for public hospitals, and $79 \%$ ( $\mathrm{n}=97)$ for private clinics. One physician responsible for the study was recruited in each centre and filled in a case record form for each patient meeting the inclusion criteria and admitted to the intensive care unit during the study recruitment period. The physicians in charge of the patients took care of them according to their usual practice and independently of the study.

\footnotetext{
Abbreviations: 4S, Scandinavian simvastatin survival study; ACE, angiotensin converting enzyme; CARE, cholesterol and recurrent events; CONSENSUS, cooperative new Scandinavian enalapril survival study; ESSENCE, efficacy and safety of subcutaneous enoxaparin in unstable angina and non-Q wave myocardial infarction; GISSI, Gruppo Italiano per lo Studio della Sopravvivenza nell'Infarto Miocardico; ISIS-4, fourth international study of infarct survival; LIPID, long-term intervention with pravastatin in ischaemic disease; LVEF, left ventricular ejection fraction; MITI, myocardial infarction triage and intervention; MONICA, monitoring trends and determinants in cardiovascular disease; NSTEMI, non-ST segment elevation myocardial infarction; $\mathrm{PCl}$, percutaneous coronary intervention; STEMI, ST segment elevation myocardial infarction; TIMI, thrombolysis in myocardial infarction
} 


\section{Patient selection}

All consecutive patients admitted to the participating centres from 1 November through 30 November 2000 were included in the study if they met the following criteria:

- Diagnosis of acute myocardial infarction based on the presence of an increase of serum markers higher than twice the upper limit of normal for creatine kinase, creatine kinase MB fraction, or troponins; and either chest pain lasting for at least 30 minutes and not relieved by nitrates or ECG changes on at least two contiguous leads with pathological Q waves (at least 0.04 seconds), or persisting ST elevation or depression $>0.1 \mathrm{mV}$.

- Time from the beginning of symptoms to admission to the intensive care unit of less than 48 hours.

Patients gave informed consent for participation in the survey and late follow up.

\section{Data collection}

The patients' cardiovascular history, their current medications at the time of admission, their risk factors (smoking status, history of hypertension or treated hypertension, cholesterol concentration $>6.5 \mathrm{mmol} / \mathrm{l}$ or treated hyperlipidaemia, family history, diabetes mellitus defined by treatment with insulin or oral antidiabetic medications, or previously documented fasting hyperglycaemia $(>6.99 \mathrm{mmol} / \mathrm{l})$, their in-hospital clinical course including maximum Killip class, and the initial diagnostic and treatment management were recorded for each patient. Furthermore, left ventricular ejection fraction (LVEF), when assessed at any time during the first five days, was recorded. The value of LVEF that was used for the present analyses was determined by the following priority ranking of the method used: firstly, left ventricular contrast angiography; secondly, radionuclide angiography; thirdly, echocardiography based on Simpson's method, fourthly, echocardiography based on the Berning wall motion index ${ }^{5}$; and lastly, echocardiography with visual estimation of LVEF.

\section{Statistical analysis}

All continuous variables, except time to admission, are reported as mean (SD). All categorical variables are described in absolute and relative frequency distributions. Groups were compared by unpaired $t$ tests for continuous variables and $\chi^{2}$ tests for discrete variables. Time to admission is expressed as median time with 25th and 75th centiles; the Mann-Whitney test was used for comparisons. Multivariate stepwise logistic regression analysis was used to assess the independent prognostic value of baseline parameters on in-hospital outcome. Variables with $\mathrm{p}<0.10$ on univariate analyses were used in the models. For all tests a $p<0.05$ was considered significant.

\section{RESULTS}

\section{Baseline parameters}

Of the 2580 patients initially considered, 260 had to be rejected because they did not meet the entry criteria (mainly for admission beyond the initial time frame of the study and unconfirmed acute myocardial infarction), so that 2320 patients were included. Median age of the population was 68 years (range $22-101$ years), and $27 \%$ of the patients were women. Non-ST segment elevation myocardial infarction (NSTEMI) was present in $17 \%$ of the patients and $83 \%$ had ST segment elevation infarction (STEMI) defined as either Q wave, ST segment elevation, or left bundle branch block on their initial ECG. Table 1 details the initial characteristics according to the type of infarction. Patients with NSTEMI were older, more often hypertensive, and had a more frequent history of cardiovascular disease. Killip class on admission, however, was not different for patients with or without STEMI.

Table 1 Baseline parameters of patients admitted for STEMI or NSTEMI

\begin{tabular}{|c|c|c|c|c|}
\hline Variable & Total $(n=2320)$ & NSTEMI $(n=398)$ & STEMI (n= 1922) & p Value \\
\hline Age (years) & & & & 0.001 \\
\hline Mean (SD) & $65(14)$ & $68(14)$ & $65(15)$ & \\
\hline Median (25th, 75th centiles) & $68(54,77)$ & $71(57,77)$ & $67(53,76)$ & \\
\hline Sex (women) & $628(27 \%)$ & $107(27 \%)$ & $521(27 \%)$ & NS \\
\hline $\mathrm{BMI} \geqslant 30$ & $362(17.5 \%)$ & $78(23 \%)$ & $284(16.5 \%)$ & 0.006 \\
\hline \multicolumn{5}{|l|}{ Risk factors: } \\
\hline Diabetes mellitus & $487(21 \%)$ & $91(23 \%)$ & $396(21 \%)$ & NS \\
\hline Past smoking & $579(25 \%)$ & $119(30 \%)$ & $460(24 \%)$ & 0.013 \\
\hline Current smoking & $754(33 \%)$ & $94(24 \%)$ & $660(34 \%)$ & 0.001 \\
\hline Hyperlipidaemia & $944(41 \%)$ & $187(47.5 \%)$ & $757(40 \%)$ & 0.005 \\
\hline Hypertension & $1076(46 \%)$ & $219(55 \%)$ & $857(45 \%)$ & 0.001 \\
\hline \multicolumn{5}{|l|}{ History } \\
\hline Previous MI & $411(18 \%)$ & $111(28 \%)$ & $300(16 \%)$ & 0.001 \\
\hline $\mathrm{CHF}$ & $149(6 \%)$ & $38(9.5 \%)$ & $111(6 \%)$ & 0.005 \\
\hline Stroke & $111(5 \%)$ & $27(7 \%)$ & $84(4 \%)$ & 0.041 \\
\hline CABG & $98(4 \%)$ & $41(10 \%)$ & $57(3 \%)$ & 0.001 \\
\hline $\mathrm{PCl}$ & $216(9 \%)$ & $63(16 \%)$ & $153(8 \%)$ & 0.001 \\
\hline PVD & $215(9 \%)$ & $49(12 \%)$ & $166(9 \%)$ & 0.022 \\
\hline Renal insufficiency & $108(5 \%)$ & $24(6 \%)$ & $84(4 \%)$ & NS \\
\hline \multicolumn{5}{|l|}{ Current episode of $\mathrm{MI}$} \\
\hline Time to admission (hours) & $5.25(2.75,14.1)$ & $6.5(2.92,17.1)$ & $5.0(2.75,14.0)$ & 0.026 \\
\hline Anterior MI & $831(36 \%)$ & 0 & $750(39 \%)$ & \\
\hline Killip class on admission & & & & NS \\
\hline 1 & $1802(78 \%)$ & $312(78 \%)$ & $1490(78 \%)$ & \\
\hline ॥ & $321(14 \%)$ & $54(14 \%)$ & $267(14 \%)$ & \\
\hline III & $131(6 \%)$ & $25(6 \%)$ & $106(5.5 \%)$ & \\
\hline IV & $62(3 \%)$ & $7(2 \%)$ & $55(3 \%)$ & \\
\hline Admission heart rate (beats/min) & $79(20)$ & $81(22)$ & $79(19)$ & 0.02 \\
\hline Initial systolic blood pressure (mm Hg) & $134(27)$ & $140(27)$ & $132(27)$ & 0.001 \\
\hline
\end{tabular}

Data are mean (SD), median (25, 75 centiles), or number (\%).

BMI, body mass index; CABG, coronary bypass grafting; CHF, congestive heart failure; MI, myocardial infarction; NS, not significant; NSTEMI, non-ST segment elevation myocardial infarction; PCI, percutaneous coronary intervention; PVD, peripheral vascular disease; STEMI, ST segment elevation myocardial infarction. 
Table 2 Medications given during the first 48 hours after hospital admission according to type of infarction

\begin{tabular}{lllll}
\hline Medication & Total $(\mathbf{n = 2 3 2 0})$ & NSTEMI $(\mathbf{n = 3 9 8 )}$ & STEMI $(\mathbf{n = 1 9 2 2 )}$ & p Value \\
\hline Unfractionated heparin & $1761(76 \%)$ & $252(63 \%)$ & $1509(78.5 \%)$ & 0.001 \\
Low molecular weight heparin & $700(30 \%)$ & $161(40.5 \%)$ & $539(28 \%)$ & 0.001 \\
Oral antiplatelet agents & $2204(95 \%)$ & $378(95 \%)$ & $1826(95 \%)$ & NS \\
GP Ilb/Illa inhibitors & $410(18 \%)$ & $54(14 \%)$ & $356(18.5 \%)$ & 0.018 \\
$\beta$ Blockers & $1654(71 \%)$ & $281(71 \%)$ & $1373(71 \%)$ & NS \\
ACE-I & $908(39 \%)$ & $125(31 \%)$ & $783(41 \%)$ & 0.001 \\
Nitrates & $1502(65 \%)$ & $307(77 \%)$ & $1195(62 \%)$ & 0.001 \\
Statins & $1045(45 \%)$ & $177(44.5 \%)$ & $868(45 \%)$ & NS \\
Diuretics & $613(26 \%)$ & $111(28 \%)$ & $502(26 \%)$ & NS \\
Digitalis & $50(2 \%)$ & $14(3.5 \%)$ & $36(2 \%)$ & 0.02 \\
Amiodarone & $205(9 \%)$ & $38(9.5 \%)$ & $167(9 \%)$ & NS \\
\hline ACE-I, angiotensin converting enzyme inhibitors; GP, glycoprotein. & & \\
\hline
\end{tabular}

\section{Initial management}

Median time from symptom onset to hospital admission was longer for patients with NSTEMI; in addition, for patients with STEMI, time to admission was strongly linked to the service that was called first: median time to admission was $4.0(2.5,8.3)$ hours for patients who called the mobile intensive care unit, $6.96(3.25,18.0)$ hours for patients who called their general practitioner first, and $10.7(4.19,24.0)$ hours for those who called their cardiologist first. Prehospital intravenous thrombolysis and hospital thrombolysis were given to $9 \%(n=180)$ and $19 \%(n=365)$ of the patients with STEMI or left bundle branch block, respectively. In addition, 484 patients (25\%) with STEMI had primary percutaneous coronary intervention (PCI) defined as PCI within 24 hours of admission without intravenous thrombolysis. Both intravenous thrombolysis and primary PCI were strongly related to the age of the patients and to the time from symptom onset. Among patients with STEMI over 70 years of age, $20 \%$ received thrombolysis and $18 \%$ received primary PCI compared with $34 \%$ and $30 \%$, respectively, of younger patients. Likewise, among patients admitted within six hours of symptom onset 39\% were given thrombolysis and $34 \%$ underwent primary PCI compared with $16 \%$ for each method among patients admitted beyond this time frame.

Table 2 lists the medications given at any time during the first 48 hours. Low molecular weight heparin and nitrates were given more often to patients with NSTEMI and glycoprotein IIb/IIIa inhibitors were used less often. There were no differences regarding $\beta$ blocking agents and statins.

\section{In-hospital outcomes}

LVEF was evaluated during the first five days in 2066 patients, most often by echocardiography. Overall, $54 \%$ of the patients had an ejection fraction $>50 \%$ and $13 \%$ had an ejection fraction $\leqslant 35 \%$; ejection fraction was less altered in patients with NSTEMI (table 3).

Table 4 lists in-hospital complications. There were essentially no differences between the two groups regarding most complications. Five day mortality was $6.1 \%$ (141 patients) and was lower for patients with NSTEMI $(3.8 \%)$ than for

Table 3 Left ventricular ejection fraction measured during the first five days

\begin{tabular}{llll}
\hline $\begin{array}{c}\text { Ejection } \\
\text { fraction }\end{array}$ & NSTEMI $(\mathbf{n = 3 5 1 )}$ & STEMI $(\mathbf{n = 1 7 1 5 )}$ & $\mathbf{p ~ V a l u e ~}$ \\
\hline$>50 \%$ & $223(63.5 \%)$ & $895(52 \%)$ & 0.001 \\
$36-50 \%$ & $96(24 \%)$ & $583(34 \%)$ & \\
$21-35 \%$ & $29(8 \%)$ & $198(11.5 \%)$ & \\
$\leqslant 20 \%$ & $3(1 \%)$ & $39(2 \%)$ & \\
\hline
\end{tabular}

those with STEMI or left bundle branch block (6.6\%). Likewise, in-hospital mortality $(8.7 \%)$ was lower for patients with NSTEMI $(5.5 \% v 9.3 \%, \mathrm{p}=0.015)$.

Table 5 lists the predictors of early mortality by univariate analysis. Multivariate regression analysis (table 6), however, showed that only nine variables were independent predictors of five day mortality: older age, higher Killip class on admission, and lower systolic arterial pressure were the three most important predictors of increased mortality (fig 1); anterior location of infarction, higher heart rate, type of infarction (with or without ST segment elevation), and previous stroke also increased the early risk of death. Current smoking and history of hyperlipidaemia were associated with a lower risk. The same variables predicted in-hospital mortality, with the addition of presence of diabetes mellitus.

\section{Medications at hospital discharge}

Table 7 lists medications at hospital discharge recorded for the 2119 hospital survivors. About 95\% received antiplatelet agents, $75 \%$ were taking $\beta$ blockers, and over $60 \%$ received statins. Angiotensin converting enzyme (ACE) inhibitors were prescribed for $40 \%$ of the patients with NSTEMI and $52 \%$ of those with STEMI. ACE inhibitor prescription was strongly linked to the level of LVEF: 39\% for patients with LVEF $>50 \%$ and more than $74 \%$ for patients with LVEF $\leqslant 35 \%$. The reverse trend was observed for $\beta$ blocking agents (fig 2).

\section{DISCUSSION}

\section{Representativeness of the study population}

The present study analysed the current management of myocardial infarction in the intensive care unit on the scale of a whole country, irrespective of the type of institution to which the patients were admitted. Participation was high at all types of institutions (academic, general hospitals, private clinics) and no imbalance was seen from one region to another. It may therefore be considered highly representative of the practice in France by the end of 2000. As the new definition of acute myocardial infarction ${ }^{6}$ was made public at the time of the survey, it is most probable that many patients with NSTEMI were not included in the registry, as they were considered to have unstable angina rather than infarction. In addition, only a minority of French centres systematically measured troponin concentrations of patients with suspected acute coronary syndromes at that time. Lastly, only patients admitted to intensive care units were included in the survey. In France, virtually all patients with STEMI are admitted to intensive care units; in contrast, it is not unusual that patients with non-ST elevation acute coronary syndromes are admitted to general wards. All of these factors probably explain why patients with NSTEMI were only a minority of 


\begin{tabular}{|c|c|c|c|c|}
\hline Variable & $\begin{array}{l}\text { Total } \\
(n=2320)\end{array}$ & $\begin{array}{l}\text { NSTEMI } \\
(\mathrm{n}=398)\end{array}$ & $\begin{array}{l}\text { STEMI } \\
(n=1922)\end{array}$ & p Value \\
\hline \multicolumn{4}{|c|}{ Maximum Killip class during first five days } & NS \\
\hline 1 & $1609(69 \%)$ & $291(73 \%)$ & $1344(70 \%)$ & \\
\hline$\|$ & $351(15 \%)$ & $50(13 \%)$ & $301(16 \%)$ & \\
\hline III & $188(8 \%)$ & $33(8 \%)$ & $155(8 \%)$ & \\
\hline IV & $165(7 \%)$ & $23(6 \%)$ & $142(7 \%)$ & NS \\
\hline Ventricular fibrillation & $81(3.5 \%)$ & $11(3 \%)$ & $70(4 \%)$ & NS \\
\hline Atrial fibrillation & $194(8 \%)$ & $36(9 \%)$ & $158(8 \%)$ & NS \\
\hline 2nd or 3rd degree AV block & $107(5 \%)$ & $6(1.5 \%)$ & $101(5 \%)$ & 0.001 \\
\hline Mitral requrgitation & $78(3 \%)$ & $13(3 \%)$ & $65(3 \%)$ & NS \\
\hline Septal or cardiac rupture & $38(2 \%)$ & $2(0.5 \%)$ & $36(2 \%)$ & 0.049 \\
\hline Stroke & $22(1 \%)$ & $3(1 \%)$ & $19(1 \%)$ & NS \\
\hline
\end{tabular}

the patient population in the present registry. Our conclusions therefore apply mainly to patients with STEMI.

\section{Characteristics of the population}

Compared with previous surveys carried out in France over the past 10 years, the proportion of diabetic patients admitted for acute myocardial infarction was higher in $2000(21 \%)$ than in $1995(17 \%)$ and similar to the findings of a survey carried out in 1998 of patients with acute coronary syndromes $(21 \%) .^{7-9}$ Patients were slightly younger than those enrolled in a similar survey carried out in $1995^{7}$; this finding is in keeping with data from the MONICA (monitoring trends and determinants in cardiovascular disease) programme in France, which also found that patients with acute myocardial infarction in recent years tended to be younger. ${ }^{10}$

\section{Initial management}

Time from symptom onset to hospital admission remained particularly long; for patients with STEMI, the median time to admission was five hours and no progress was observed in this regard compared with the French 1995 survey. ${ }^{7}$ Several mechanisms may explain this excessive time delay. One important factor may be the tendency of patients to deny the cardiac origin of chest pain, and this factor is probably one of the most difficult to correct. ${ }^{11}{ }^{12}$ However, the present study also shows that, once a patient has decided to call a doctor, the first person to be contacted is decisive in the time delay before hospital admission; median times before hospital admission were four hours when emergency medical services were called, compared with nearly seven hours when the general practitioner was called and 11 hours when the cardiologist was called. Continued efforts should be made to encourage patients to contact emergency medical services when they have prolonged chest pain. Recent experiments have shown that a media campaign directed at the public can improve this situation. ${ }^{13} 14$

Reperfusion therapy was given to only $53 \%$ of patients with STEMI, Q waves, or left bundle branch block; this rather low figure is explained mainly by the time delay from symptom onset to hospital admission, but also by a much lower use of reperfusion therapy for older patients, despite the evidence that reperfusion therapy, including thrombolysis, is beneficial for these patients as well. ${ }^{15} 16$ Similar rates of reperfusion therapy have been reported in other registries reflecting real world practice in various countries. ${ }^{17-19}$ Intravenous thrombolysis remained the most widely used method of reperfusion and nearly one patient in 10 received thrombolysis before hospital admission (that is, in the mobile intensive care unit). Among patients receiving reperfusion therapy, the proportion of patients treated with primary PCI $(47 \%)$, however, was higher than previously observed, either in France or in several other countries. ${ }^{78-20}$

A substantial proportion of the patients were treated with low molecular weight heparin, particularly in the case of NSTEMI (40\%), which reflects the impact of the results of the TIMI (thrombolysis in myocardial infarction) $11 \mathrm{~B}$ and ESSENCE (efficacy and safety of subcutaneous enoxaparin

Table 5 Univariate predictors of five day mortality in the whole population

\begin{tabular}{|c|c|c|}
\hline & Five day mortality & p Value \\
\hline Age $<70 / \geqslant 70$ years & $29(2 \%) / 112(11 \%)$ & 0.001 \\
\hline Men/women & $85(5 \%) / 56(9 \%)$ & 0.001 \\
\hline Hypertension/no hypertension & $67(6 \%) / 72(6 \%)$ & NS \\
\hline Diabetes mellitus/no diabetes mellitus & $46(9 \%) / 95(5 \%)$ & 0.001 \\
\hline $\mathrm{BMI} \geqslant 30 /<30$ & $11(3 \%) / 73(4 \%)$ & NS \\
\hline Hyperlipidaemia/no hyperlipidaemia & $39(4 \%) / 98(7 \%)$ & 0.008 \\
\hline Previous smoking/no previous smoking & $33(6 \%) / 102(6 \%)$ & NS \\
\hline Current smoking/no current smoking & $17(2 \%) / 120(8 \%)$ & 0.001 \\
\hline Previous $\mathrm{Ml} /$ no previous $\mathrm{Ml}$ & $24(6 \%) / 117(6 \%)$ & NS \\
\hline Previous $\mathrm{CHF} /$ no previous $\mathrm{CHF}$ & $15(10 \%) / 125(6 \%)$ & NS \\
\hline Previous stroke/no previous stroke & $18(16 \%) / 123(6 \%)$ & 0.001 \\
\hline Previous $\mathrm{CABG} /$ no previous $\mathrm{CABG}$ & $3(3 \%) / 138(6 \%)$ & NS \\
\hline Previous $\mathrm{PCl} /$ no previous $\mathrm{PCl}$ & $5(2 \%) / 136(6.5 \%)$ & 0.035 \\
\hline PVD/no PVD & $19(9 \%) / 122(6 \%)$ & NS \\
\hline Admission Killip class I/II/III/IV & $54(3 \%) / 37(11.5 \%) / 18(14 \%) / 32(52 \%)$ & 0.001 \\
\hline Admission heart rate $>90 / \leqslant 90$ beats $/ \mathrm{min}$ & $62(12 \%) / 79(4 \%)$ & 0.001 \\
\hline Admission arterial pressure $<116 / 116-130 / 131-150 />150 \mathrm{~mm} \mathrm{Hg}$ & $71(12.5 \%) / 24(4 \%) / 23(4 \%) / 20(4 \%)$ & 0.001 \\
\hline STEMI/NSTEMI & $126(7 \%) / 15(4 \%)$ & 0.022 \\
\hline Anterior $\mathrm{Ml} /$ no anterior $\mathrm{Ml}$ & $71(8.5 \%) / 69(5 \%)$ & 0.001 \\
\hline No reperfusion/pre-hospital thrombolysis/in-hospital thrombolysis/primary $\mathrm{PCl}$ & $88(7 \%) / 4(2 \%) / 26(7 \%) / 23(5 \%)$ & NS \\
\hline
\end{tabular}


Table 6 Multivariate predictors of five day mortality and in-hospital mortality

\begin{tabular}{|c|c|c|c|c|c|c|}
\hline & \multicolumn{3}{|c|}{ Five day mortality } & \multicolumn{3}{|c|}{ In-hospital mortality } \\
\hline & $\overline{O R}$ & $95 \% \mathrm{Cl}$ & p Value & $\overline{O R}$ & $95 \% \mathrm{Cl}$ & p Value \\
\hline Age $\geqslant 70$ years & 3.57 & 2.13 to 5.99 & 0.0001 & 3.64 & 2.36 to 3.21 & 0.0001 \\
\hline $\begin{array}{l}\text { Admission systolic arterial pressure } \\
<116 \mathrm{~mm} \mathrm{Hg}^{*}\end{array}$ & 2.56 & 1.69 to 3.88 & 0.0001 & 2.49 & 1.73 to 3.57 & 0.0001 \\
\hline Killip class ( $v$ class I) & & & 0.0001 & & & 0.0001 \\
\hline II or III & 2.02 & 1.28 to 3.19 & & 2.24 & 1.52 to 3.30 & \\
\hline IV & 12.90 & 6.58 to 25.31 & & 11.84 & 6.12 to 22.92 & \\
\hline Anterior MI & 1.67 & 1.12 to 2.49 & 0.012 & 1.52 & 1.08 to 2.14 & 0.018 \\
\hline Admission heart rate $>90$ beats $/ \mathrm{min} \dagger$ & 1.69 & 1.11 to 2.59 & 0.015 & 1.76 & 1.22 to 12.54 & 0.002 \\
\hline Previous stroke & 2.11 & 1.10 to 4.05 & 0.025 & 1.86 & 1.04 to 3.33 & 0.036 \\
\hline STEMI & 2.05 & 1.06 to 3.95 & 0.033 & 1.93 & 1.13 to 3.30 & 0.016 \\
\hline Hyperlipidaemia & 0.63 & 0.41 to 0.97 & 0.034 & NA & NA & NA \\
\hline Current smoking & 0.52 & 0.27 to 0.98 & 0.044 & 0.58 & 0.34 to 0.98 & 0.042 \\
\hline Diabetes mellitus & NA & NA & NA & 1.47 & 1.01 to 2.13 & 0.043 \\
\hline
\end{tabular}

in unstable angina and non-Q wave myocardial infarction) trials on everyday practice..$^{21} 22$ Fewer than $20 \%$ of the patients were treated with glycoprotein IIb/IIIa inhibitors, mainly patients who underwent early angiography and PCI. $\beta$ Blocking agents were given to over $70 \%$ of the patients and $45 \%$ of patients received statins within two days of hospital admission. This finding may be explained in that statin administered early during acute coronary syndromes has no deleterious effect and that patients who do not receive secondary prevention medications during the initial hospital
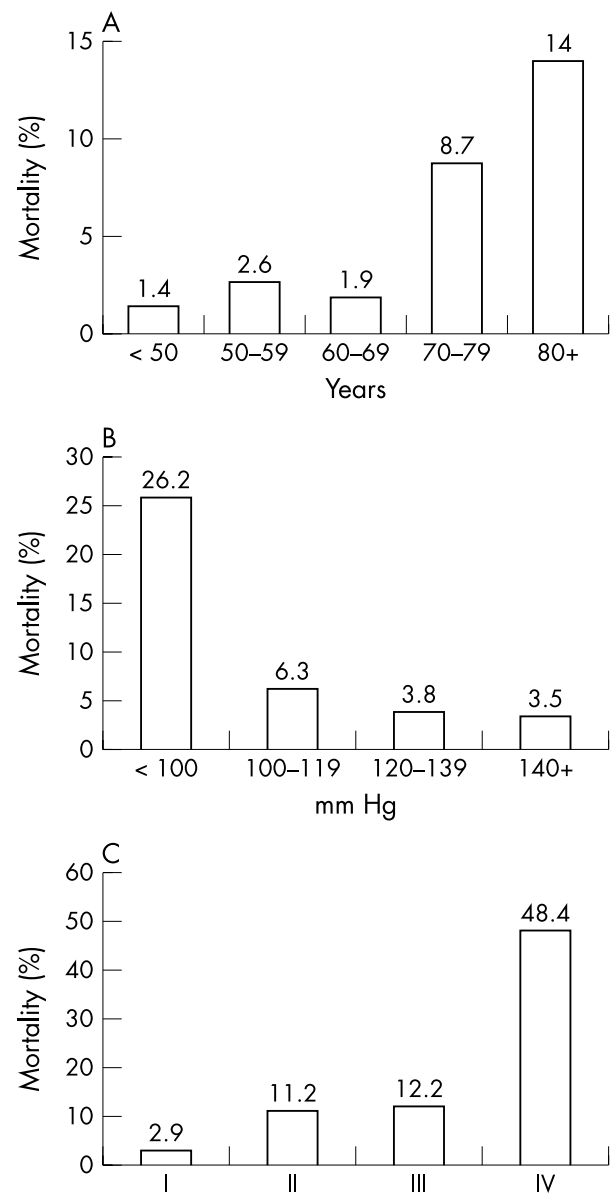

Figure 1 In-hospital mortality according to (A) age, (B) systolic arterial pressure measured at hospital admission, and (C) Killip class. stay are less likely to be treated later on. ${ }^{23}{ }^{24}$ In contrast, no more than $40 \%$ of the patients received ACE inhibitors, even though the ISIS-4 (fourth international study of infarct survival) and GISSI (Gruppo Italiano per lo Studio della Sopravvivenza nell'Infarto Miocardico) -3 trials have documented the beneficial effect of early administration of these medications to patients with myocardial infarction. ${ }^{25} 26$ French cardiologists seem to reserve ACE inhibitors for patients with impaired left ventricular function.

\section{In-hospital complications}

Among patients who had in-hospital complications, 3.5\% had ventricular fibrillation and $8.4 \%$ had atrial fibrillation, a figure lower than what was observed in the previous French survey. ${ }^{7}$ Five day mortality was $6.1 \%$, which is a $21 \%$ relative reduction compared with five day mortality reported in the French 1995 survey (7.7\%) and a nearly 100\% reduction compared with a previous survey carried out in France in mostly academic institutions in $1984(12.1 \%) .^{727}$ In-hospital mortality was $8.7 \%$. Reductions in in-hospital mortality in the past two decades have also been observed in most industrialised countries. ${ }^{28-30}$ Among predictors of early mortality, anterior infarct location, older age, and Killip class on admission were expected. Interestingly, low blood pressure on admission and high heart rate on admission were also potent prognostic factors for in-hospital mortality, independently of Killip class on admission. This finding emphasises the prognostic importance of haemodynamic parameters reflecting the neurohormonal balance very early in the course of acute myocardial infarction; it also emphasises the potential benefit of early administration of $\beta$ blockers and the potential deleterious effect of pharmacologically induced hypotension in this setting (CONSENSUS (cooperative new Scandinavian enalapril survival study) II trial). ${ }^{31}$ In this regard, the fact that over $60 \%$ of the patients received nitrates at the early stage, despite the negative results of the GISSI-3

Table 7 Medications at hospital discharge

\begin{tabular}{llll}
\hline Medication & NSTEMI $(\mathbf{n}=\mathbf{3 7 8})$ & STEMI $(\mathbf{n}=1755)$ & $\mathbf{p}$ Value \\
\hline Antiplatelet & & & \\
agents & $353(93.4 \%)$ & $1661(94.6 \%)$ & $\mathrm{NS}$ \\
$\beta$ Blockers & $274(72.5 \%)$ & $1331(75.8 \%)$ & $\mathrm{NS}$ \\
ACE-I & $150(39.7 \%)$ & $916(52.2 \%)$ & 0.001 \\
Statins & $226(59.8 \%)$ & $1124(64.0 \%)$ & $\mathrm{NS}$ \\
Three drugs & $177(47 \%)$ & $918(53 \%)$ & 0.049 \\
Four drugs & $65(17 \%)$ & $502(29 \%)$ & 0.001
\end{tabular}




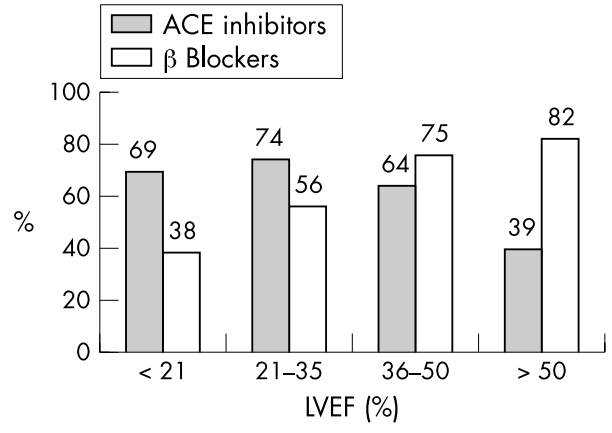

Figure 2 Prescription of $\beta$ blockers and angiotensin converting enzyme (ACE) inhibitors at hospital discharge according to left ventricular ejection fraction.

and ISIS-4 trial, appears disturbing. ${ }^{25}{ }^{26}$ It is surprising that neither a previous myocardial infarction nor a history of congestive heart failure was associated with early outcome; one might speculate on the role of secondary prevention medications in these patients already known to have coronary artery disease. As previously observed, early reperfusion therapy was not an independent predictor of early outcome, as the benefits of such treatment are usually observed later in the course of the disease. ${ }^{32}$ Likewise, there was no difference in early outcome between the use of intravenous thrombolysis and the use of primary coronary angioplasty. The lack of an early prognostic impact of reperfusion therapy was already observed in the previous French registry carried out in 1995, as well as in other registries such as the MITI (myocardial infarction triage and intervention) registry. ${ }^{73}$

\section{Medications prescribed at discharge}

Much progress has been made in the prescription of secondary prevention medications at hospital discharge. Antiplatelet agents are prescribed for $95 \%$ of patients, $\beta$ blockers for three patients in four, and ACE inhibitors for one patient in two. These figures indicate a slight improvement over previous surveys carried out in the second part of the 1990s. ${ }^{7-9}$ The prescription of statins, in contrast, has increased dramatically from $10 \%$ in 1995 to over $60 \%$. Though the results of the heart protection study were not yet available when the survey was carried out, results of the $4 \mathrm{~S}$ (Scandinavian simvastatin survival study), CARE (cholesterol and recurrent events), and LIPID (long-term intervention with pravastatin in ischaemic disease) trials seem to have convinced French cardiologists of the appropriateness of prescribing statins for patients who have sustained an acute myocardial infarction. ${ }^{34-37}$ As a result, half of the patients received triple combination treatment (antiplatelet agents, $\beta$ blockers, and statins) and a quarter, quadruple combination treatment (antiplatelet agents, $\beta$ blockers, statins, and ACE inhibitors) at hospital discharge. This is a huge increase in the prescription of combined treatment at hospital discharge, compared with the previous 1995 survey. ${ }^{38}$ Elderly patients $(\geqslant 70$ years of age) were less often prescribed both $\beta$ blockers (55\% $\vee 81 \%$ ) and statins (44\% $v 70 \%)$, however, although there is no evidence of a reduced efficacy in this population.

\section{Conclusion}

The present survey of $83 \%$ of all institutions taking care of patients with acute myocardial infarction in France by the end of 2000 shows continued improvement in in-hospital outcome, compared with previous surveys. Reperfusion therapy, however, was given to barely more than $50 \%$ of the patients, a finding partially explained by the still much too long time delay between symptom onset and hospital admission: in this regard, no improvement whatsoever was found, compared with the previous 1995 nationwide survey. In contrast, continued improvement was apparent in the rates of prescription of secondary prevention medications at hospital discharge, with more than half of the population receiving triple (antiplatelet, $\beta$ blocker, and statin) treatment at that time. Both the improvement in early outcome and the higher rate of prescription of secondary prevention medications at discharge are likely to result in improved long term outcome.

\section{ACKNOWLEDGEMENTS}

The authors are indebted to all physicians in the participating centres, without whose collaboration this study would not have been possible. This study was supported by a grant from Laboratoire Aventis, Paris, France

\section{Authors' affiliations}

G Hanania, CH Aulnay, France

P Guéret, CHU Henri Mondor, Crétell, France

D Blanchard, N Danchin, Service de Cardiologie, HEGP, Paris, France

J M Lablanche, Hôpital Cardiologique, CHRU de Lille, France

J-P Cambou, INSERM U 558, Toulouse, France

L Vaur, Y Boutalbi, N Genès, Laboratoire Aventis, Paris, France

R Humbert, $\mathrm{P}$ Clerson, Orgamétrie, Wasquehal, France

\section{REFERENCES}

1 Van de Werf F, Ardissino D, Betriu A, et al. The task force on the management of acute myocardial infarction of the European Society of Cardiology. Management of acute myocardial infarction in patients presenting with STsegment elevation. Eur Heart J 2003;24:28-66.

2 Ryan TJ, Antman EM, Brooks NH, et al. 1999 updated guideline (web version). ACC/AHA guidelines for the management of patients with acute myocardial infarction. A report of the American College of Cardiology/ American Heart Association task force on practice guidelines (committee on management of acute myocardial infarction). www.acc.org/clinical/ guildelines/nov96/1999/index.htm (accessed 20 Jun 2004).

3 Hasdai D, Behar S, Wallentin L, et al. A prospective survey of the characteristics, treatments and outcomes of patients with acute coronary syndromes in Europe and the Mediterranean basin: the Euro heart Survey of acute coronary syndromes (Euro heart survey ACS). Eur Heart $J$ 2002; 23:1190-201.

4 Marciniak TA, Ellerbeck EF, Radford MJ, et al. Improving the quality of care for Medicare patients with acute myocardial infarction: results from the cooperative cardiovascular project. JAMA 1998;279:1351-7.

5 Berning J, Steenegaard-Hansen F. Early estimation of risk by echocardiographic determination of wall motion index in an unselected population with acute myocardial infarction. Am J Cardiol 1990;65:567-76.

6 The Joint European Society of Cardiology/American College of Cardiology Committee. Myocardial infarction redefined. A consensus document of the Joint European Society of Cardiology/American College of Cardiology committee for the redefinition of myocardial infarction. Eur Heart $J$ 2000;21:1502-13.

7 Danchin N, Vaur L, Genès N, et al. Management of acute myocardial infarction in intensive care units in 1995: a nationwide French survey of practice and early hospital results. J Am Coll Cardiol 1997;30:1598-605.

8 Danchin N, Grenier O, Ferrières J, et al. Use of secondary preventive drugs in patients with acute coronary syndromes treated medically or with coronary angioplasty: results from the nationwide French PREVENIR survey. Heart 2002;88:159-62.

9 Marques-Vidal P, Cambou JP, Ferrières J, et al. Distribution et prise en charge des facteurs de risque cardiovasculaires chez des patients coronariens: étude Prévenir. Arch Mal Coeur 2001;94:673-80.

10 Haas B, Arveiler D, Cambou JP, et al. Prise en charge thérapeutique de l'infarctus du myocarde: évolution dans le projet MONICA-France entre 1985 et 1991. Rev Epidemiol Sante Publique 1996;44:S53-61.

11 Brown AM, Mann C, Daya M, et al. Demographic, belief, and situational factors influencing the decision to utilize emergency medical services among chest pain patients. Circulation 2000;102:173-8

12 Arveiler D, Bingham A, Escudero I, et al. Evaluation des conditions d'accès aux soins d'urgence des sujets atteints d'infarctus du myocarde. Rev Epidemiol Sante Publique 1988;36:350-9.

13 Gaspoz JM, Unger PF, Urban P, et al. Impact of a public campaign on prehospital delay in patients reporting chest pain. Heart 1996;76:150-5.

14 Chevalier V, Alauze C, Soland V, et al. Intérêt d'une campagne d'information régionale sur les urgences cardiaques et l'appel au 15. Ann Cardiol Angéiol (Paris) 2003;52:150-8.

15 White HD. Thrombolytic therapy in the elderly. Lancet 2000;356:2028-30.

16 Danchin N, Angioi M, Demicheli T, et al. Effect of reperfusion therapy on longterm outcome in patients $>70$ years of age. Am J Cardiol 2002;90:1142-5. 
17 Gottlieb S, Harpaz D, Shotan A, et al. Sex differences in management and outcome after acute myocardial infarction in the 1990s: a prospective observational community-based study. Circulation 2000;102:2484-90.

18 Heer T, Schiele R, Schneider S, et al. Gender differences in acute myocardial infarction in the era of reperfusion (the MITRA registry). Am J Cardiol 2002;89:51 1-7.

19 Daverman HL, Lessard D, Yarzebski J, et al. Ten-year trends in the incidence treatment, and outcome of myocardial infarction. Am J Cardiol 2000;86:730-5.

20 Rogers WJ, Canto JG, Lambrew CT, et al. Temporal trends in the treatment of over 1.5 million patients with myocardial infarction in the U.S. from 1990 to 1999. The national registry of myocardial infarction 1, 2, and 3. J Am Coll Cardiol 2000;36:2056-63.

21 Cohen M, Demers C, Gurfinkel EP, et al. A comparison of low molecularweight heparin with unfractionated heparin for unstable coronary artery disease. Efficacy and Safety of Subcutaneous Enoxaparin in non-Q-wave Coronary Events Study Group. N Engl J Med 1997;337:447-52.

22 Antman EM, McCabe CH, Gurfinkel EP, et al. Enoxaparin prevents death and cardiac ischemic events in unstable angina/non-Q-wave myocardial infarction: results of the thrombolysis in myocardial infarction (TIMI) $11 \mathrm{~B}$ trial. Circulation 1999;100:1593-601.

23 Pitt B, Waters D, Brown WV, for the atorvastatin versus revascularization treatment investigators, et al. Aggressive lipid lowering therapy compared with angioplasty in stable coronary artery disease. N Engl J Med 1999;341:70-6.

24 Butler J, Arbogast PG, BeLue R, et al. Outpatient adherence to beta-blocker therapy after acute myocardial infarction. J Am Coll Cardiol 2002;40:1589-95.

25 Anon. Gruppo Italiano per lo Studio della Sopravvivenza nell'Infarto Miocardico. GISSI-3: effects of lisinopril and transdermal glyceryl trinitrate singly and together on 6-week mortality and ventricular function after acute myocardial infarction. Lancet 1994;343:1115-22.

26 ISIS-4 Collaborative Group. ISIS-4: a randomised factorial trial assessing early captopril, oral mononitrate, and intravenous magnesium sulphate in 58,050 patients with suspected myocardial infarction, ISIS-4 (fourth international study of infarct survival) collaborative group. Lancet 1995;345:669-85.

27 Groupe de travail « Epidémiologie et prevention » de la Société Française de Cardiologie. Fréquence et conditions d'hospitalisation des infarctus récents du myocarde en France. L'enquête nationale ENIM 84. Arch Mal Coeur 1987;80:1853-63.

28 Behar S, Goldbout U, Barbash G, et al. Twenty-five year mortality rate decrease in patients in Israel with a first episode of acute myocardial infarction. Secondary Prevention Reinfarction Israeli Nifedipine Trial Study Group. Israeli Thrombolytic Survey Group. Am Heart J 1995;130:453-8

29 Greenbaum RA, Morris R, Sritara P, et al. Reduced in-hospital mortality from acute myocardial infarction with general adoption of thrombolytic therapy in the North West Thames health region 1979-1991. Br Heart $J$

1995;74:493-6.

30 Furman MI, Daverman HL, Goldberg RJ, et al. Twenty-two year (1975-1997) trends in the incidence, in-hospital and long-term case fatality rates from initial Q-wave and non-Q-wave myocardial infarction: a multi-hospital, communitywide perspective. J Am Coll Cardiol 2001;37:1571-80.

31 Swedberg K, Held P, Kjekshus J, et al. Effects of the early administration of enalapril on mortality in patients with acute myocardial infarction: results of the cooperative new Scandinavian enalapril survival study II (CONSENSUS II). N Engl J Med 1992;327:678-84.

32 Fibrinolytic Therapy Trialists' Collaborative Group. Indications for fibrinolytic therapy in suspected acute myocardial infarction: collaborative overview of early mortality and major morbidity results from all randomised trials of more than 1000 patients. Fibrinolytic Therapy Trialists' (FFT) collaborative group. Lancet 1994;343:311-22

33 Maynard C, Weaver D, Litwin PE, for the MITI project investigators, et al. Hospital mortality in acute myocardial infarction in the era of reperfusion therapy (the myocardial infarction triage and intervention project) Am J Cardiol 1993;72:877-82.

34 Heart Protection Study Collaborative Group. MRC/BHF heart protection study of cholesterol lowering with simvastatin in 20536 high-risk individuals: a randomized placebo-controlled trial. Heart protection study collaborative group. Lancet 2002;360:7-22.

35 Scandinavian Simvastatin Survival Study Group. Randomised trial of cholesterol lowering in 4444 patients with coronary heart disease: the Scandinavian simvastatin survival study (4S). The Scandinavian simvastatin survival study group. Lancet 1994;344:1383-9.

36 Sacks FM, Pfeffer MA, Moye LA, et al. The effect of pravastatin on coronary events after myocardial infarction in patients with average cholesterol levels. Cholesterol And Recurrent Events Trial Investigators. N Engl J Med 1996;335:1001-9.

37 LIPID Study Group. Prevention of cardiovascular events and death with pravastatin in patients with coronary heart disease and a broad range of initial cholesterol levels. The long-term intervention with pravastatin in ischaemic disease (LIPID) study group. N Engl J Med 1998;339:1349-57.

38 Danchin N, Hanania G, Grenier O, et al, pour les investigateurs USIK 1995, PREVENIR1, PREVENIR 2 et USIC 2000. Evolution du traitement de sortie après hospitalisation pour syndrome coronaire aigu en France entre 1995 et 2000: données des études USIK 1995, PREVENIR 1 et 2 et USIC 2000. Ann Cardiol Angéiol (Paris) 2003;52:1-6.

\section{IMAGES IN CARDIOLOGY}

doi: $10.1136 /$ hrt.2004.03588

An isolated single coronary artery supplying the entire myocardium in a patient with congenitally corrected transposition of the great vessels

A

25 year old man with a history of congenitally corrected transposition of the great vessels was referred for cardiac catheterisation before possible surgical management of systemic atrioventricular valve regurgitation. The catheterisation was notable for the finding of a single coronary artery supplying the entire myocardium (panels A and B).

The incidence of an isolated single coronary artery is noted to be $0.07 \%$ of adults referred for coronary arteriography. However, the incidence is much higher in patients with congenital heart disease and in particular those with conotruncal malformations. Approximately a third of the cases of isolated coronary arteries have been reported in the setting of transposition of the great vessels and tetrology of Fallot. Several authors have noted that $19 \%$ of patients undergoing coronary angiography in the setting of truncus arteriosus, $17 \%$ of patients in the setting of pulmonary atresia, and $2 \%$ in the
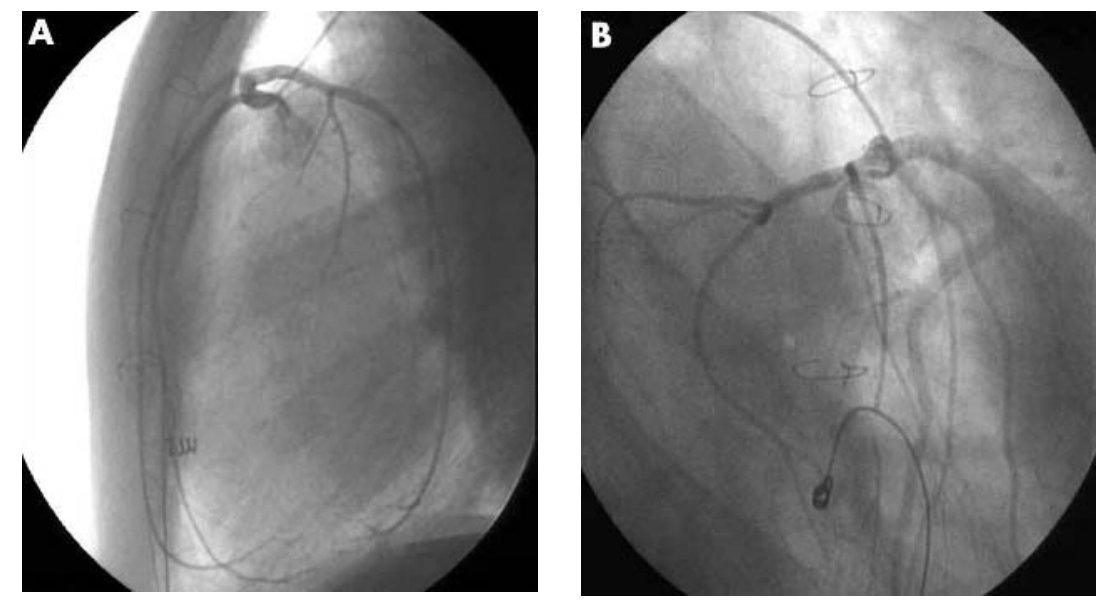

setting of tetrology of Fallot have the finding of an isolated single coronary artery. It is important to know the presence of anomalies of the coronary arteries before cardiac surgery, especially in the setting of congenital heart disease, in order to minimise the risk of accidental ligation or transection.

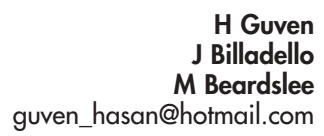

